\section{Monitoring the presence of domoic acid in the produc- tion areas of bivalve molluscs}

\author{
Rachele Rossi, Olga Arace, \\ Maria Giovanna Buonomo, \\ Daniela Capozzo, Vincenzo Castellano, \\ Samantha Imbimbo, Vittorio Soprano
}

Institute for Experimental Veterinary Medicine of Southern Italy, Portici (NA), Italy

\section{Abstract}

Algal biotoxins, chemical compounds produced by some microscopic algae, constitute the phytoplankton. The mussels, feeding on phytoplankton, can accumulate these compounds to become themselves toxic. There have been several cases of food poisoning by consumption of contaminated shellfish. Such food poisoning have pushed our health care system to provide monitoring of shellfish in the framework of the monitoring plans carried out by AASSLL. In this paper we report the results obtained monitoring the presence of amnesic shellfish poisoning biotoxins, like domoic acid and its isomers, produced by Pseudonitzschia algae. The analyses were carried out by using both the high-performance liquid chromatography-ultraviolet official method and an experimental method performed with a time-offlight mass spectrometer (ESI-TOF). The 100\% of samples analysed by the official method have always been below the limits of sensitivity (except one sample), and the $65 \%$ of samples analysed by ESI-TOF showed the presence of domoic acid.

\section{Introduction}

Domoic acid (DA) (Figure 1) is a neurotoxin produced by several species of phytoplankton, predominantly of the diatom genus Pseudo-nitzschia. This toxin enters food webs through feeding interactions and can accumulate in higher trophic levels (Costa et al., 2005; Doucette et al., 2006). Human consumption of DA-contaminated shellfish causes amnesic shellfish poisoning (ASP). A regulatory action level of $20 \mu \mathrm{g} \mathrm{DA} / \mathrm{g}$ shellfish tissue is employed world wide for the harvesting and consumption of shellfish resources to protect human health (Reg. 853/2004; European Commission, 2004). High performance liquid chromatography (HPLC) with photodiode array detection (DAD) is the most popular method used for the determination of DA in shellfish tissue, devel- oped by Quilliam and Wright (1989) now modified as the EU-harmonised-SOP-ASP-HPLCUV Version 1 (AEASAN, 2008), using a reversed phase column, under isocratic elution, and an optical absorbance detection at $242 \mathrm{~nm}$. LC coupled to mass spectrometry (MS) detection has also been used for the determination of DA (Wang et al., 2007) but to today this method was complex and costly. We here report a method for the determination of the neurotoxin domoic acid (DA) in shellfish using LC-TOF/MS, which is really sensitive and provides a higher resolution allowing for the detection of also all the isomers of domoic acid. Studies in fish zebrafish (Danio rerio) (Tiedekena et al., 2005; Hong et al., 2015), treated with low but constant levels of domoic acid, showed damage to the brain system as well as to the cardiovascular system.

\section{Materials and Methods}

Domoic acid reference material was purchased from Sigma Aldrich (Saint Louis, MO, USA). Acetonitrile, methanol and water were HPLC grade. Trifluoroacetic acid was obtained from VWR International (Milan, Italy).

The official method was performed on an Agilent 1200 instruments equipped with quaternary pump and an auto sampler. Phenomenex Synergi $4 \mu$ Polar-RP $80 \mathrm{~A}$ $(250 \times 4.60 \mathrm{~mm})$ thermostated at $40^{\circ} \mathrm{C}$ was used for chromatographic separation. The isocratic mobile phase, consisting of a mixture of $1 \%$ aqueous trifluoroacetic acid and acetonitrile in the ratio 90:10 (v/v), was used. The flow rate was $1 \mathrm{~mL} / \mathrm{min}$. Sample solutions (8, 4, 2, $0.4 \mathrm{ppm}$ ) were prepared in ACN/W (1:9) and 20 $\mu \mathrm{L}$ was injected.

The HPLC-UV analysis worked in optical absorbance detection at $242 \mathrm{~nm}$ and major peaks of DA was eluted approximately at 12'.

The high-resolution method was performed using an Agilent 1100 instruments equipped with binary pump and an auto sampler. Phenomenex Luna $3 \mu$ PFP $(150 \times 2.00 \mathrm{~mm})$ was used for chromatographic separation, this column has the unique chemistry of a pentafluorophenyl which increases selectivity and reproducibility of compounds. The isocratic mobile phase consisted of a mixture of $0.1 \%$ aqueous acetic acid and acetonitrile in the ratio $90: 10(\mathrm{v} / \mathrm{v})$ was used. The flow rate was $0.2 \mathrm{~mL} / \mathrm{min}$. Sample solutions $(0.4,0.2,0.1$, $\left.0.05,0.025,0.0125,0.00625 \mathrm{ppm}, \mathrm{R}^{2}=0.985\right)$ were prepared in ACN/W (1:9) and $5 \mu \mathrm{L}$ was injected.

The ESI/TOF analysis worked in positive mode, and mass range was set at $m / z$ 100-650 $\mathrm{u}$ at a resolving power of 10,000 . The conditions of ESI source were as follows: drying gas $\left(\mathrm{N}_{2}\right)$ flow rate, $8 \mathrm{~mL} / \mathrm{min}$; drying gas tempera-
Correspondence: Vittorio Soprano, Institute for Experimental Veterinary Medicine of Southern Italy, via Salute 2,80055 Portici (NA), Italy. Tel: +39.081 .7865338 - Fax: +39.0817865342 .

E-mail: v.soprano@izsmportici.it

Key words: Domoic acid; Production areas; Bivalve molluscs.

Received for publication: 21 December 2016. Revision received: 13 May 2016.

Accepted for publication: 16 May 2016.

This work is licensed under a Creative Commons Attribution-NonCommercial 4.0 International License (CC BY-NC 4.0).

(C) Copyright R. Rossi et al., 2016

Licensee PAGEPress, Italy

Italian Journal of Food Safety 2016; 5:5706

doi:10.4081/ijfs.2016.5706

ture, $300^{\circ} \mathrm{C}$; nebuliser, 45 psig; capillary voltage, $4000 \mathrm{~V}$; fragmentor $225 \mathrm{~V}$; skimmer voltage, $60 \mathrm{~V}$. Acquisition and analysis of data were controlled by Agilent LC-MS TOF Software (Agilent, Santa Clara, CA, USA). Tuning mix (G1969-85001) was used for lock mass calibration in our assay. Under these conditions, major peaks of DA appeared as the protonated ion at $m / z 312$, being accompanied by minor peaks consisting of sodium-binding ions at $\mathrm{m} / \mathrm{z}$ 334 and the ion fragment $m / z 266$ represents loss of $\mathrm{HCOOH}$ from the protonated DA ion (Figure 2). The fragmentation pattern observed was found to be highly diagnostic for these molecules which, combined with the retention time, provide a high specificity for the molecule identification.

The limit of detection is about 0.00125 $\mathrm{mg} / \mathrm{kg}$. The quantitation limit for domoic acid by this method is, at least, $0.005 \mathrm{mg} / \mathrm{kg}$. The method has been tested for domoic acid determination by Quasimeme proficiency test providing always satisfactory results.

182 mussel samples were analysed since January 1 till July 31, 2015 by the official method in HPLC-UV (Quilliam and Wright, 1989) and among these, 78 were selected randomly for ESI-TOF analysis.

The procedure for handling shellfish tissue was based on that published by the official method and was followed without modifications. Bivalve mollusc were cleaned free of shell before initiating the extract protocol on the remaining soft components. DA was extracted from the mussels tissue by homogenisation with methanol-water (1:1, $\mathrm{v} / \mathrm{v}) .100 \mathrm{~g}$ of mussel tissue was homogenised with the blender. $4 \mathrm{~g}$ of this homogenate tissue were placed in a $50 \mathrm{~mL}$ plastic conical tube and combined with $16 \mathrm{~mL}$ of extraction solvent (50\% aqueous methanol) and homogenised again for 2 min to facilitate extraction of DA by 
the solvent. The mixture was then either centrifugated at $3000 \mathrm{rpm}$ for 10 minutes and the supernatant, representing the sample extract, was injected in the HPLC-UV or, for the ESITOF analysis, filtered again through a $0.22 \mu \mathrm{m}$ pore diameter membrane (Millipore) and centrifugated at $12,000 \mathrm{rpm}$ for 10 minutes. The sample was stored in a glass vial at $+4^{\circ} \mathrm{C}$ until analysed.

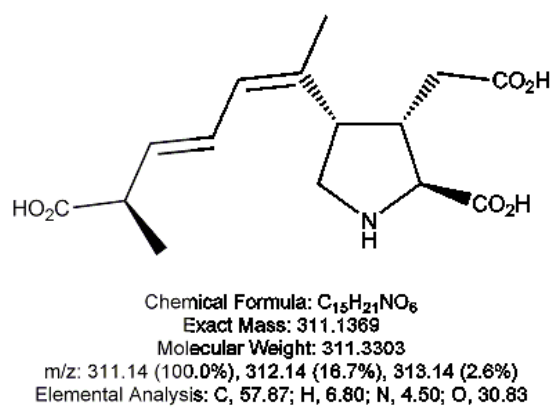

Figure 1. Domoic acid structure.

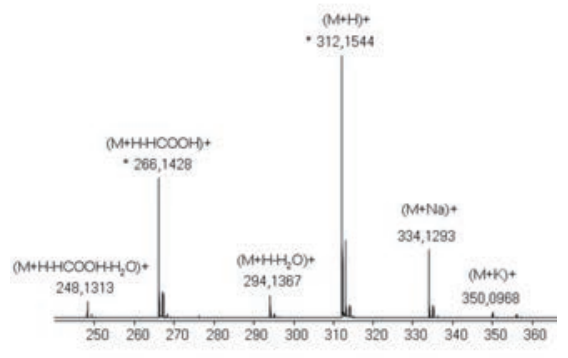

$(\mathrm{m} / \mathrm{z})$

Figure 2. Domoic acid characteristic ion pattern obtained by electrospray ionization-time-of-flight mass spectrometry.

\section{Results and Discussion}

The results of 182 samples of mussels have always been below the limits of sensitivity of the official method (with the exception of one sample quantified by $3.1 \mathrm{mg} / \mathrm{kg}$; Figure 3 ).

In the mussel sample quantified by 3.1 $\mathrm{mg} / \mathrm{kg}$ the official method is capable to identify only the domoic acid itself, whereas the ESITOF method allowed us to identify the presence of the toxin and its isomers (Figure 4). The identity of the domoic acid isomers is only supposed because of the lack of their reference material for the certain identification.

Among the 78 mussel samples analysed by ESI-TOF, 51 (65\%) showed the presence of domoic acid whereas in 27 (35\%) the amount of biotoxin was not quantifiable $(<0.00125$ $\mathrm{mg} / \mathrm{kg}$ ).

\section{Conclusions}

Current analytical techniques used to detect environmental contaminants are generally designed to target only a fraction of these compounds and have not yet been adapted to the detection and the identification of unknown substances. It is however crucial to study the presence of contaminants at lower levels compared to the official limits. New analytical techniques are thus necessary to screen for the presence of contaminants and their degradation products in environmental samples. High resolution-mass spectrometry is a promising technique that has the potential to address the shortcomings of present analytical techniques. The analysis performed by the official method, from January 2015 to late July
2015, gave always accordant results: the amount found showed lower levels than the regulatory action level $(20 \mathrm{mg} / \mathrm{kg})$. The analysis performed by ESI-TOF, more sensitive, has instead revealed a frequent presence of domoic acid. The presence of this toxin, albeit minimal, it still indicates the presence of toxic algae blooms such Pseudonitzschia whose sudden must always be kept under control. Although the monitoring programs under way seems to be effective in preventing acute poisoning by algal biotoxins, repeated exposure to low levels of toxins may cause long-term consequences (which have yet to be identified).

\section{References}

AEASAN, 2008. EU-harmonised standard operating procedure for determination of domoic acid in shellfish and finfish by RPHPLC using UV detection. Version 1. Agencia Española de Seguridad Alimentaria y Nutrición, Vigo, Spain. Available from: www.aesan.msssi.gob.es/ CRLMB/docs/docs/procedimientos/EUHarmonised-SOP-AS P-HPLC-UV_ Version1.pdf

Costa PR, Rosa R, Duarte-Silva A, Brotas V, Sampayo MAM, 2005. Accumulation, transformation and tissue distribution of domoic acid, the amnesic shellfish poisoning toxin, in the common cuttlefish, Sepia officinalis. Aquat Toxicol 74:82-91.

Doucette GJ, Maneiro I, Riveiro I, Svensen C, 2006. Phycotoxin pathways in aquatic food webs: transfer, accumulation and degradation. In: Granéli E, Turner JT, eds. Ecology of harmful algae. Springer-Verlag, Heidelberg, Germany, pp 283-95.

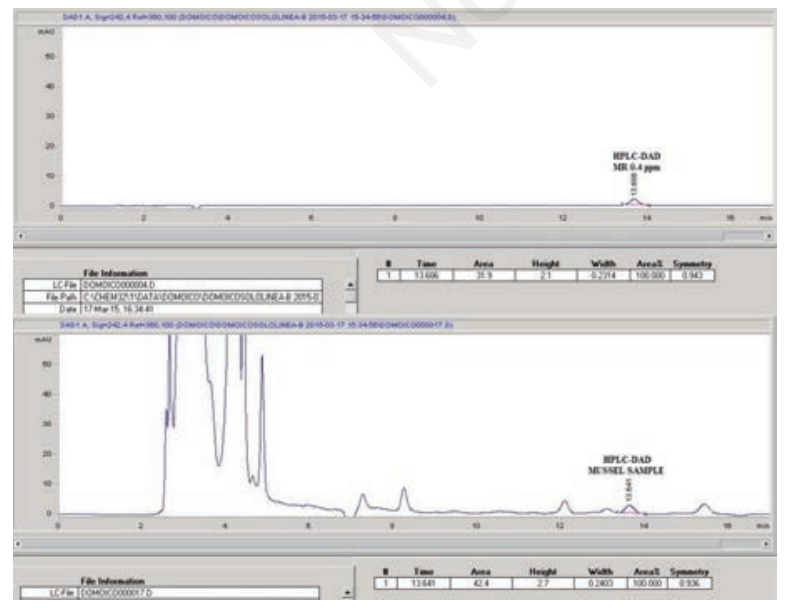

Figure 3. Domoic acid chromatograms obtained by high-performance liquid chromatography with diode-array detection, in the reference material (upper panel) and in the mussel sample (lower panel).

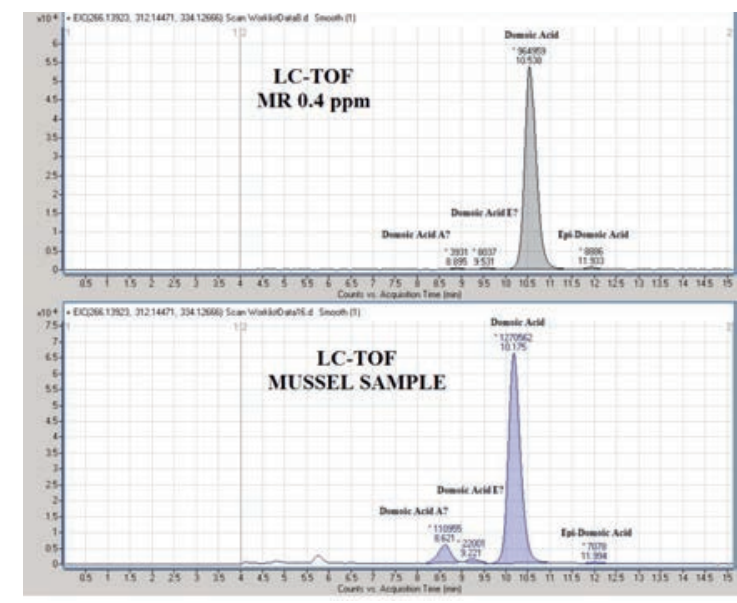

Figure 4. Domoic acid chromatograms obtained by liquid chromatography time-of-flight mass spectrometry, in the reference material (upper panel) and in the mussel sample (lower panel). 
European Commission, 2004. Regulation of the European Parliament and of the Council of 29 April 2004 laying down specific hygiene rules for on the hygiene of foodstuffs, 853/2004/EC. In: Official Journal, L 139/55, 30/04/2004.

Hong Z, Zhang Y, Zuo Z, Zhu R, Gao Y, 2015. Influences of domoic acid exposure on car- diac development and the expression of cardiovascular relative genes in zebrafish (Danio rerio) embryos. J Biochem Mol Toxicol 29:254-60.

Quilliam MA, Wright JLC, 1989. The amnesic shellfish poisoning mystery. Anal Chem 61:1053-9.

Tiedekena JA, Ramsdell JS, Ramsdell AF, 2005.
Developmental toxicity of domoic acid in zebrafish (Danio rerio). Neurotoxicol Teratol 27:711-7.

Wang Z, King KL, Ramsdell JS, Doucette GJ, 2007. Determination of domoic acid in seawater and phytoplankton by liquid chromatography-tandem mass spectrometry. J Chromatogr A 1163:169-76. 